\title{
Pulse oximetry in sickle cell disease
}

\author{
P Pianosi, T D Charge, D W Esseltine, A L Coates
}

\begin{abstract}
Patients with sickle cell disease usually have mild hypoxaemia and their oxyhaemoglobin dissociation curve is shifted to the right. It follows that oxygen saturation in sickle cell disease should be lower than normal. Most subjects in this clinic had normal oxygen saturation by pulse oximetry, however. To improve the understanding of this paradox, arterialised capillary oxygen tension $\left(\mathrm{Po}_{2}\right)$ and oxygen saturation were compared with simultaneously measured pulse oximeter saturation in 20 children with sickle cell disease. In addition, the $\mathrm{Po}_{2}$ at $50 \%$ haemoglobin saturation $\left(\mathbf{P}_{50}\right)$ was compared with saturation measured by pulse oximetry in all 20 patients. It was found that saturation measured by pulse oximetry was, on the whole, similar to that calculated from the sampled blood. Individual deviations were not random, however, and were partly explained by differences in $\mathbf{P}_{\mathbf{5 0}}$ values. It is concluded that pulse oximetry gives variable results in patients with sickle cell disease and should be used with caution to predict arterial saturation in this patient group. (Arch Dis Child 1993; 68: 735-738)
\end{abstract}

The use of pulse oximetry is becoming more common in routine clinical practice with the advent of inexpensive, portable oximeters. ' This has allowed non-invasive measurement of oxygen saturation $\left(\mathrm{SpO}_{2}\right)$ within $2 \%$ of that measured spectrophotometrically at oxygen saturation values $>75 \%$. $^{2}$

Hypoxaemia has been reported in children with sickle cell disease. ${ }^{3}$ The arterial oxygen tension $\left(\mathrm{PaO}_{2}\right)$ values in this study ranged from 8.64 to $11.30 \mathrm{kPa}(65-85 \mathrm{~mm} \mathrm{Hg})$, which would normally correlate with saturations in the range 91-97\%. The oxyhaemoglobin dissociation curve is known to be shifted to the right in sickle cell disease. ${ }^{4}$ Thus we were surprised to find that most patients with sickle cell disease in our clinic had normal $(\geq 95 \%) \quad \mathrm{Spo}_{2}$ values, whereas intuitively we expected that most patients would have borderline or low values for $\mathrm{SpO}_{2}$. To improve our understanding of the assessment of pulmonary gas exchange in sickle cell disease, we sampled arterialised capillary blood in 20 patients, from which saturation was calculated, and compared this with saturation measured by pulse oximetry. We then compared $\mathrm{Spo}_{2}$ and $\mathrm{P}_{50}$ $\left(\mathrm{Po}_{2}\right.$ at $50 \%$ haemoglobin saturation) values to see if there was any relation between the magnitude of shift in the oxyhaemoglobin dissociation curve and $\mathrm{SpO}_{2}$. We also plotted the oxyhaemoglobin dissociation curve with data from four patients with sickle cell disease to verify that a curve shifted to the right would result in $\mathrm{SaO}_{2}$ $\leq 95 \%$ in a subject breathing ambient air with a normal alveolar-arterial oxygen gradient. Based on our clinical impression, we hypothesised that pulse oximeter saturation would overestimate true arterial saturation, and that this would be seen particularly in patients with the greater rightward shift (higher $\mathrm{P}_{50}$ ) in their oxyhaemoglobin dissociation curve, who physiologically should have lower oxygen saturation.

\section{Subjects and methods}

Venous blood was obtained from 20 patients with sickle cell disease at the time of a routine clinic visit. All were well and had not received a transfusion in the preceding three months. The haemoglobin concentration was measured by standard methods. The value of $P_{50}$ was determined as follows. Five millilitres of heparinised blood were obtained and then divided into two equal aliquots. Each aliquot was placed into the cuvette of one of two tonometers (IL 237). With the water bath preheated to $37^{\circ} \mathrm{C}$ and kept constant throughout, a test gas was pumped through each cuvette at $400 \mathrm{ml} / \mathrm{min}$. The test gases used were $5 \%$ carbon dioxide balance nitrogen and $5 \%$ carbon dioxide balance oxygen such that blood in one tonometer would be fully saturated while that in the other desaturated (co-oximeter $\mathrm{So}_{2}<5 \%$ ). After 15 minutes of blood-gas equilibration aliquots of blood were withdrawn from each cuvette in varying ratios such that total volume was approximately $0.5 \mathrm{ml}$. A few stainless steel pellets were added to the syringe and, with the outlet sealed, the syringe was shaken to ensure adequate mixing of saturated and desaturated blood. We avoided prolonged periods of desaturation in the process, or repeated deoxy-oxygenation cycles, as these have been shown to lead to irreversible biophysical changes in red cells with sickle haemoglobin $(\mathrm{HbS}) .^{5}$ The blood was then analysed for $\mathrm{pH}, \mathrm{Po}_{2}$, and carbon dioxide tension $\left(\mathrm{PCO}_{2}\right)$ (Radiometer ABL30) and oxygen saturation (Radiometer OSM2 Hemoximeter). The $\mathrm{Po}_{2}$ value obtained was corrected to a standard $\mathrm{pH}$ of $7 \cdot 40$ using an IL $\mathrm{Po}_{2} \mathrm{pH}$ nomogram (Instrumentation Laboratory). The points obtained were then plotted using $\mathrm{Po}_{2}$ on the abscissa and $\mathrm{SaO}_{2}$ on the ordinate. $\mathrm{P}_{50}$ (the $\mathrm{Po}_{2}$ at $50 \%$ saturation) was determined using three to four points in the 40$60 \%$ saturation range by linear interpolation. Using a larger amount of blood from four of these patients the entire oxyhaemoglobin dissociation curve was plotted, fitting a sigmoid curve by eye, to eight to 10 data points for each patient. To obtain better resolution for curve fitting, two oxyhaemoglobin dissociation curves were constructed by combining $\mathrm{Po}_{2}$ and $\mathrm{So}_{2}$ data from patients with similar $\mathbf{P}_{50}$ values. This was carried out to verify that there was a right shifted oxyhaemoglobin dissociation curve in our patient group. To validate our methodology, blood from two controls (HbAA) was also obtained for 

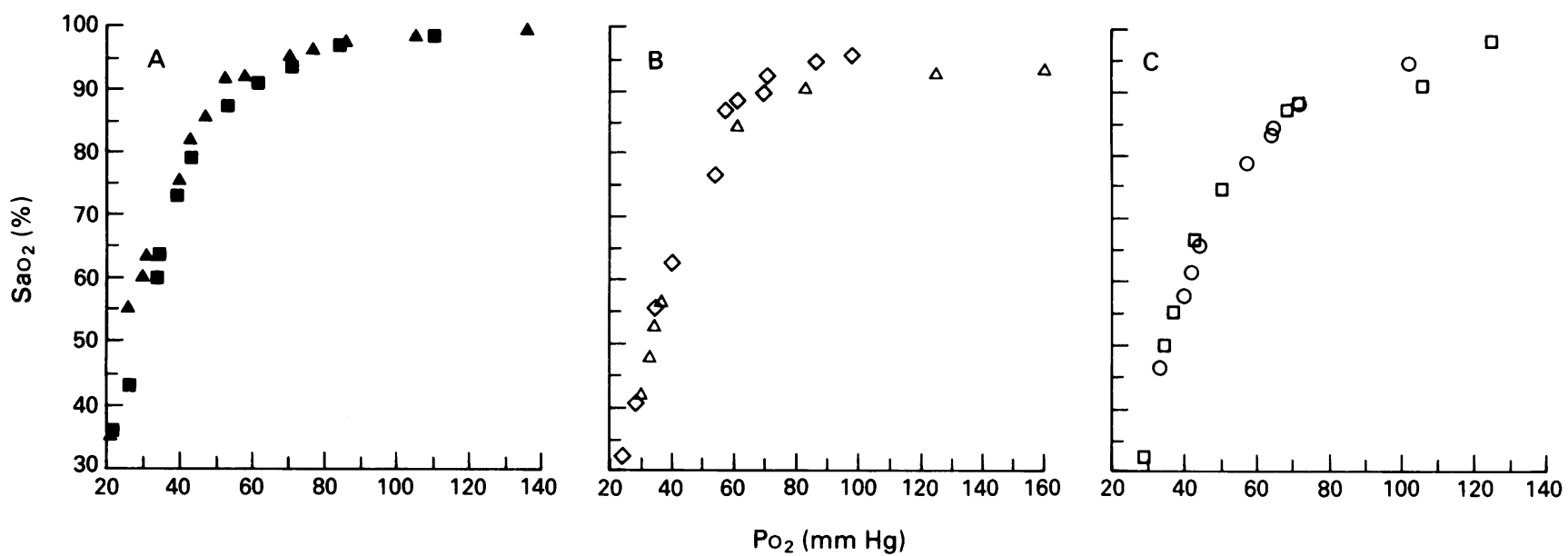

Figure 1 Plot of the oxyhaemoglobin dissociation curves for patients with sickle cell disease (open symbols, one shape for each patient) in (B) and (C). The curve derived from normal haemoglobin is shown for comparison (closed symbols) in (A). Note different abscissae for each plot ( $1 \mathrm{kPa}=7 \cdot 5 \mathrm{~mm} \mathrm{Hg}$ ).

comparison, as the $\mathrm{P}_{50}$ in healthy sea level inhabitants is well known.

A Nellcor N-200 pulse oximeter in the fast response, electrocardiogram synchronous mode was used to measure transcutaneous oxygen saturation. This was performed at rest with the patient seated on an exercise bicycle, and at the same time as $\mathrm{PaO}_{2}$ was obtained by arterialised capillary blood sampling from a fingertip during steady state exercise at $50 \%$ maximum work capacity. ${ }^{6}$ The hand was wrapped in a heated cloth for five minutes before sampling, the finger pierced with a lancet, and after wiping away the first drop, free flowing blood was collected into two or three capillary tubes. The tubes were immediately put on ice, and within 20 minutes, $\mathrm{Po}_{2}, \mathrm{PCO}_{2}$, and $\mathrm{pH}$ were measured on a blood gas analyser (Radiometer ABL 3). Saturation $\mathrm{SaO}_{2}$ was calculated from this sample by the Kelman digital computer subroutine. ${ }^{7}$

Saturation data determined by pulse oximetry and calculated from arterialised capillary blood were compared by linear regression techniques. tion were then correlated with $\mathbf{P}_{50}$. Relationships between $P_{50}$ and other variables were also explored by linear regression analysis, using a personal computer based program (Minitab). Differences between the two measures of satura-

\section{Results}

Figure 1 shows the sickle cell oxyhaemoglobin dissociation curve, together with one derived from controls. The $P_{50}$ values for this subgroup of patients were 32.5 and 33.5 (fig $1 \mathrm{~B}$ ), and 35.0 and $35 \cdot 2$ (fig 1C). Comparison of the calculated saturation with the pulse oximeter derived saturation for the entire group of 20 patients is shown in fig $2 \mathrm{~A}$. The regression line for the comparison had a slope of $1 \cdot 05$, not significantly different from the line of identity. The relation just achieved statistical significance $(p=0 \cdot 04)$, however, as there was wide scatter about the line of identity (standard deviation $3 \cdot 7 \%$ saturation). Differences between the two measurements of saturation are shown in fig $2 \mathrm{~B}$, plotted against $P_{50}$. It can be appreciated that pulse oximetry tended to overestimate arterial saturation in patients with only a slightly right shifted oxyhaemoglobin dissociation curve, but tended to underestimate saturation in those with markedly right shifted curves.

The table shows the mean $\mathrm{P}_{50}$, haemoglobin, saturation, and $\mathrm{Po}_{2}$ values for all 20 patients. There was an inverse correlation between $\mathrm{P}_{50}$ and haemoglobin concentration $(r=0.48 ; \mathrm{p}=$ 0.006). Subjects with sickle cell disease had resting $\mathrm{SpO}_{2}$ values ranging from 82 to $100 \%$,
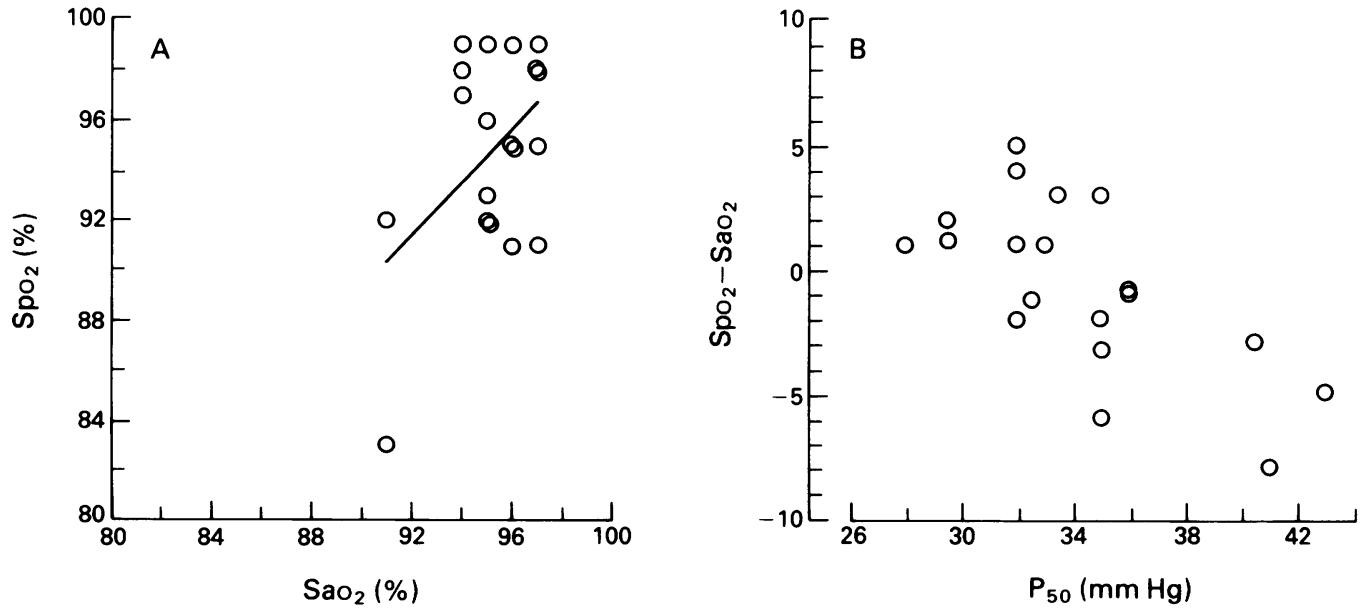

Figure 2 (A) Plots of simultaneously measured $\mathrm{SpO}_{2}$ and $\mathrm{SaO}_{2}$ and $(\mathrm{B})$ of the difference between the two as a function of $P_{50}$ $(1 \mathrm{kPa}=7 \cdot 5 \mathrm{~mm} \mathrm{Hg}$ ). 
Clinical characteristics of the group of patients with sickle cell disease

\begin{tabular}{llllll}
\hline & Haemoglobin $(\mathrm{g} / \mathrm{l})$ & $\mathrm{P}_{50}(\mathrm{~mm} \mathrm{Hg})$ & $\mathrm{SpO}_{2}(\%)$ & $\mathrm{SaO}_{2}{ }^{\star}(\%)$ & $\mathrm{PaO}_{2}(\mathrm{kPa})$ \\
\hline Mean & 100 & $34 \cdot 0$ & $94 \cdot 9$ & $95 \cdot 5$ & $10 \cdot 26$ \\
Range & $65-113$ & $27 \cdot 3-42 \cdot 8$ & $82-100$ & $91-97$ & $7.99-12.52$
\end{tabular}

$\star$ Calculated $\mathrm{SaO}_{2}$.

with only five less than $95 \%(94,93,93,92$, and $82 \%)$. The $P_{50}$ values of these five were $3 \cdot 86(29)$, $4 \cdot 26$ (32), 5.72 (43), 4.12 (31), and 5.45 (41) $\mathrm{kPa}(\mathrm{mm} \mathrm{Hg})$ respectively. Looking at the data differently, three patients had markedly increased $P_{50}$ values $(>5.3 \mathrm{kPa}, 40 \mathrm{~mm} \mathrm{Hg}$ ), with $\mathrm{SpO}_{2}$ measurements of 91,92 , and $82 \%$, and calculated $\mathrm{SaO}_{2}$ values of 96,95 , and $91 \%$. As expected, there was no statistically significant relation between $\mathrm{SaO}_{2}$ and $\mathrm{P}_{50}$, but there was a significant relation $(\mathrm{p}=0.003)$ between $\mathrm{Spo}_{2}$ and $P_{50}$, even after exclusion of the outlying point (fig 3).

\section{Discussion}

We have shown that, in general, pulse oximetry provides a reasonably accurate measurement of oxygen saturation in patients with sickle cell disease, but that its value is suspect in predicting a given subject's arterial saturation. It is clear that results can be widely ( $\geq 4 \%$ ) discrepant in some instances, with overestimates and underestimates of true arterial saturation observed. Furthermore, the magnitude and direction of the error are not random, and depend on $\mathbf{P}_{50}$.

There are several possible explanations for the variable and sometimes conflicting data comparing pulse oximetry with measured arterial saturation, and for the paucity of lower $\mathrm{SpO}_{2}$ values in our patient group. Jubran and Tobin reported inaccurate oximetry readings $(>4 \%$ difference between saturation measured by a pulse oximeter and co-oximeter) were more common in black than in white patients. ${ }^{9}$ If fig 4 of their paper is examined, it is clear that pulse oximeter measurements were consistantly above $90 \%$ whereas saturation co-oximetry values ranged from 78 to $97 \%$. Skin pigmentation should not affect the $\mathrm{SpO}_{2}$ values measured by the two wavelength pulse oximeter as the light beam 'reads' pulsatility in the absorption phenomenon. As pointed out by these workers, however, dark skin pigmentation may interfere with

Figure 3 Plot of pulse oximeter $\mathrm{SpO}_{2}$ versus $P_{50}$ in patients with sickle cell disease ( $1 \mathrm{kPa}=7 \cdot 5$ $\mathrm{mm} \mathbf{H g}$ ). absorption at the wavelengths used in pulse oximetry. The possibility of inaccurate $\mathrm{SpO}_{2}$ values in black subjects has also been shown during exercise and hypoxia. ${ }^{10}$ In that study the eight wavelength oximeter fared better than any two wavelength device, the latter generally overestimating true $\mathrm{SaO}_{2}$. Another potential factor causing suspect $\mathrm{SpO}_{2}$ measurements in sickle cell disease was emphasised in a review of noninvasive monitoring of blood gases. " The scattering of the light emitted by the sensor as it passes through tissues depends on the geometry of the red blood cell. If this red blood cell geometry in the patient does not match that of subjects from whom the empirical calibration graph of the oximeter's algorithm was derived (which is probable in patients with sickle cell disease), then significant measurement error may result.

We are not suggesting all pulse oximetry values are unrealiable in patients with sickle cell disease. The large differences noted by Jubran and Tobin occurred in only $27 \%$ of their subjects. ${ }^{9}$ The clinical dilemma lies in deciding in which patients pulse oximetry is misleading, and in which patients it is reliable. This is not a trivial dilemma. It may mean as little as a patient receiving more oxygen than is actually needed. Alternatively, it may mean that a series of investigations into the cause of 'desaturation' is launched needlessly if oximetry alone is used to assess the adequacy of pulmonary gas exchange.

The right shift in the oxyhaemoglobin dissociation curve in anaemia, quantitated by $P_{50}$, is considered a compensatory mechanism whereby oxygen bound to haemoglobin with reduced affinity will be released more readily to the tissues where $\mathrm{Po}_{2}$ is low. ${ }^{12}$ The $\mathrm{P}_{50}$ value of our patients ranged from 3.46 to $5.72 \mathrm{kPa}(26-43$ $\mathrm{mm} \mathrm{Hg}$ ), and was inversely related to haemoglobin concentration, in agreement with previous studies. $^{413}$ In some patients with anaemia, increased $P_{50}$ is due to the accumulation of 2,3diphosphoglycerate (DPG) in the red cell. ${ }^{12}$ In sickle cell disease, it is the presence of $\mathrm{HbS}$ which reduces the affinity for oxygen, although the 2, 3-DPG concentration may actually be low. ${ }^{14}$ Whereas the magnitude of the difference between $\mathrm{SpO}_{2}$ and $\mathrm{SaO}_{2}$ was correlated with the haemoglobin concentration and $\mathrm{P}_{50}$, stepwise multiple regression analysis showed that almost all the variance was explained by $P_{50}$. This leads us to speculate that the presence of $\mathrm{HbS}$ in the erythrocyte causes a peculiar dispersion pattern of the incident infrared light used by the two wavelength pulse oximeter, and this accounts for our findings.

We believe that the use of arterialised capillary $\mathrm{Po}_{2}$ was valid, because the mean $\mathrm{Po}_{2}$ of our patients was similar to that reported by Wall et al who measured resting arterial $\mathrm{Po}_{2}{ }^{3}$ Thus we do not feel that the calculated $\mathrm{SaO}_{2}$ was biased by artificially low $\mathrm{Po}_{2}$. Because of the shape of the oxyhaemoglobin dissociation curve, we would normally expect saturation to lie within a narrow range despite $\mathrm{PaO}_{2}$ varying from 9.31 to $13.3 \mathrm{kPa}$ (70-100 $\mathrm{mm} \mathrm{Hg})^{3}$ Thus pulse oximetry might be relatively insensitive to mild degrees of hypoxaemia, considering the precision of the pulse oximeter. ${ }^{2}$ Given that most patients with sickle 
cell disease have some degree of hypoxaemia and that nearly all have a right shifted oxyhaemoglobin dissociation curve, however, it was somewhat puzzling that a broader range of $\mathrm{SpO}_{2}$ values in our patient group was not observed.

It is clear that a study comparing $\mathrm{SpO}_{2}$ and arterial $\mathrm{SO}_{2}$ determined by co-oximeter in patients with sickle cell disease is warranted. Until a better understanding of the relation between pulse oximetry and true arterial saturation is found, periodic arterial blood gas sampling, especially at times of clinical pulmonary disease, would appear essential for pulse oximetry to be a useful tool in management of sickle cell disease.

Dr Pianosi was a fellow of the Canadian Cystic Fibrosis Foundation.

1 Tobin MJ. State of the art: respiratory monitoring in the intensive care unit. Am Rev Respir Dis 1988; 138: 1625-42.

2 Chapman KR, Liu FLW, Watson RM, Rebuck AS. Range of accuracy of two wavelength oximetry. Chest 1986; 89:540-2 . Wall MA, Platt OS, Streider DJ. Lung function in children with sickle cell anemia. Am Rev Respir Dis 1979; 120:210-4.
4 Becklake MR, Griffiths SB, McGregor M, Goldman HI, Schreve JP. Oxygen dissociation curves in sickle cell anemia and in subjects with sickle cell trait. $\mathcal{F}$ Clin Invest 1954; 34 : $751-5$.

5 Horiuchi K, Asakura T. Formation of light irreversibly sickled cells during deoxygenation-oxygenation cycles. sickled cells during deoxygenation-oxygenation cycles.

6 Pianosi P, D'Souza SJA, Charge TD, Esseltine DW, Coates AL. Cardiac output and oxygen delivery during exercise in AL. Cardiac output and oxygen delivery during exercise
sickle cell anemia. Am Rev Respir Dis 1991; 143: 231-5.

7 Kelman GR. Digital computer subroutine for the conversion of oxygen tension into saturation. $\mathcal{F}$ Appl Physiol 1966; 21 : 1375-6.

8 Fowler NO, Smith O, Freenfield JC. Arterial blood oxygen in sickle cell anemia. Am 7 Med Sci 1957; 234: 449-58.

9 Jubran A, Tobin MJ. Reliability of pulse oximetry in titrating supplemental oxygen therapy in ventilator-dependent patients. Chest 1990; 97: 1420-5.

10 Zeballos RJ, Weisman IM. Reliability of noninvasive oximetry in black subjects during exercise and hypoxia. Am Rev in black subjects during exe

11 Clark JS, Votteri B, Ariagno RL, et al. Noninvasive assessment of blood gases. Am Rev Respir Dis 1992; 145: 220-32.

12 Torrance J Jacobs P, Restrepo J, Eschbach C, Lenfant C Torrance J, Jacobs P, Restrepo J, Eschbach C, Lenfant C,
Finch CA. Intraerythrocytic adaptation to anemia. N Engl f Med 1970; 283: 165-9.

13 Bromberg PA, Jensen WN. Blood oxygen dissociation curves in sickle cell disease. F L ab Clin Med 1967; 70: 480-7.

14 Seakins M, Gibbs WN, Milner PF, Bertles JF. Erythrocyte $\mathrm{HbS}$ concentration. An important factor in the low oxygen affinity of blood in sickle cell anemia. $\mathcal{F}$ Clin Invest 1973; 52 422-32. 